\title{
Immunologic sensitization in recipients of left ventricular assist devices
}

\author{
Ranjit John, MD ${ }^{a}$ \\ Katherine Lietz, MD \\ Michael Schuster, BS ${ }^{a}$ \\ Yoshifumi Naka, MD \\ Vivek Rao, MD ${ }^{\mathrm{a}}$ \\ Donna M. Mancini, $M D^{\mathrm{b}}$ \\ Eric A. Rose, $M^{a}$ \\ Craig R. Smith, MD \\ Mehmet C. Oz, MD \\ Niloo M. Edwards, MD \\ Silviu Itescu, MD ${ }^{\mathrm{a}}$
}

\footnotetext{
From the Departments of Surgery ${ }^{\mathrm{a}}$ and Cardiology, ${ }^{\mathrm{b}}$ Columbia University College of Physicians and Surgeons, New York, NY.

Read at the Twenty-seventh Annual Meeting of The Western Thoracic Surgical Association, San Diego, Calif, June 20-23, 2001.

Received for publication June 28, 2001; revisions requested Aug 28, 2001; revisions received Jan 22, 2002; accepted for publication April 12, 2002.

Address for reprints: Ranjit John, MD, Division of Cardiothoracic Surgery, Columbia Presbyterian Medical Center, Milstein Hospital Building 7-435, New York, NY 10032 (E-mail: ranjitj@pol.net).

J Thorac Cardiovasc Surg 2003;125:578-91

Copyright (C) 2003 by The American Association for Thoracic Surgery

0022-5223/2003\$30.00+0

doi: $10.1067 / \mathrm{mtc} .2003 .30$
}

Objective: Left ventricular assist device implantation is associated with an increased risk of development of circulating anti-HLA class I and II antibodies (sensitization). We investigated the impact of sensitization on posttransplantation outcomes in 105 consecutive left ventricular assist device recipients.

Methods: Five hundred twenty-one consecutive adult cardiac allograft recipients between 1992 and 1999 were retrospectively studied. Of these, 105 were supported with a left ventricular assist device. Pretransplantation and posttransplantation antibody production, time to transplantation after listing, rejection, freedom from transplant coronary artery disease, and survival were evaluated by Kaplan-Meier analysis. Among sensitized left ventricular assist device recipients, 26 were treated with a pretransplantation immunomodulatory regimen consisting of intravenous immunoglobulin and cyclophosphamide.

Results: There were no significant differences between left ventricular assist device recipients and nonbridged recipients with respect to pretransplantation demographic characteristics and $\mathrm{ABO}$ and HLA matching. Among left ventricular assist device recipients, 66\% (69/105) were sensitized before transplantation; in contrast, only $6 \%$ $(24 / 399)$ of nonbridged recipients were sensitized $(P<.001)$. Sensitized untreated left ventricular assist device recipients had both a prolongation of waiting time to transplantation and an increased risk of acute rejection. Pretransplantation immunomodulatory therapy reduced both the increased waiting time and the increased risk of acute rejection. However, sensitization or the use of immunomodulatory therapy in left ventricular assist device-bridged recipients did not influence posttransplantation survival relative to nonbridged recipients.

Conclusions: Left ventricular assist device recipients have survival outcomes similar to those of nonbridged recipients after cardiac transplantation, despite their significantly higher immunologic risk. The reduced rate of transplantation and the increased incidence of rejection observed in sensitized left ventricular assist device recipients are prevented by immunomodulatory therapy. Sensitization will remain an important issue with increased use of left ventricular assist devices, and improved understanding of this is essential to achieve better outcomes in the management of patients with end-stage heart failure. 


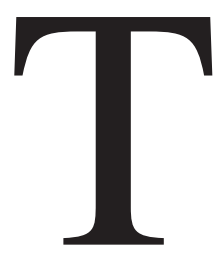

he development of circulating antibodies, termed sensitization, may occur as a result of previous blood transfusions, previous pregnancies, a previous allograft, and, more recently, the presence of a left ventricular assist device (LVAD). ${ }^{1,2}$ It is well known that human renal allografts in sensitized recipients may undergo fulminant rejection within minutes or hours of revascularization. ${ }^{3}$ This pattern of hyperacute rejection almost never occurs today because of current immunologic monitoring protocols. In a 1969 landmark study, Patel and Terasaki ${ }^{4}$ established that a prospective negative crossmatch between donor lymphocytes and recipient serum is the single best predictor of short-term allograft survival. The presence of preformed lymphocytotoxic antibodies reactive against donor lymphocytes in recipient serum (a positive donor-specific crossmatch) is considered a contraindication to solid organ transplantation because of the high incidence of humoral allograft rejection, increased risk of early graft failure, and poorer patient survival..$^{5-7}$ Current standards in kidney transplantation mandate a crossmatch between donor-recipient pairs before transplantation. However, constraints of prolonged ischemic time do not allow crossmatching to be a routine test in cardiac transplantation. A much less precise surrogate to ensure immunologic compatibility has been the use of panel reactive antibody (PRA) testing.

The proportion of highly sensitized patients on cardiac transplant waiting lists has been progressively expanding in recent years as a result of widespread use of left ventricular assist devices (LVAD) and increasing numbers of patients undergoing retransplantation. ${ }^{8,9}$ LVAD recipients have prominent B-cell activation, as evidenced by heightened production of anti-HLA class I and class II immunoglobulin $\mathrm{G}$ (IgG) antibodies. ${ }^{10}$ Although use of leukocyte-filtered platelets can partially reduce anti-HLA class I antibody production, B-cell hyperreactivity associated with

LVAD implantation results from a multifactorial dysregulatory process involving heightened T-cell apoptosis, selective loss of $\mathrm{T}_{\mathrm{H}} 1$ type $\mathrm{T}$ cells, and unopposed production of $\mathrm{T}_{\mathrm{H}} 2$ cytokines. ${ }^{11}$ As a consequence of circulating anti-HLA class I and class II antibodies, LVAD recipients are subject to repeated positive crossmatches, increased waiting time to cardiac transplantation, and heightened risk of cellular rejection after transplantation. In this large single-center study we investigated the impact of sensitization in LVAD recipients on posttransplantation outcomes relative to nonbridged cardiac allograft recipients and evaluated the influence of immunologically focused interventions to prevent the adverse immunologic and clinical effects of sensitization on LVAD recipients undergoing cardiac transplantation.

\section{Methods \\ Patients}

Between January 1992 and November 1999, a total of 521 consecutive primary transplants were performed on adult (age $>18$ years) recipients at the Columbia Presbyterian Medical Center. The patients were predominantly male $(78.1 \%)$ and white $(81.3 \%)$, with a mean age of $50.8 \pm 12.7$ years. The major pretransplantation diagnosis was ischemic cardiomyopathy $(62 \%)$, followed by idiopathic cardiomyopathy (26\%), congenital heart disease $(5 \%)$, and others $(7 \%)$. One hundred five patients $(20 \%)$ were supported with LVADs before transplantation.

\section{Clinical Data}

The following pretransplantation variables were analyzed: recipient age, recipient sex, recipient ethnicity, pretransplantation diagnosis, pretransplantation cytomegalovirus infection, donor age, donor sex, donor race, ischemic time, and HLA-A, HLA-B, and HLA-DR mismatches. The pretransplantation development of IgG anti-HLA class I and II antibodies and waiting time to transplantation were evaluated as part of the pretransplantation analysis. In the posttransplantation period, data on acute rejection, transplantrelated coronary artery disease (TCAD), and survival were evaluated and compared between the groups.

\section{Operative Techniques}

Hearts were harvested from beating-heart, brain-dead donors. Graft procurement and preservation used cold cardioplegic arrest with University of Wisconsin solution and topical hypothermia. From 1992 through 1996, orthotopic cardiac transplantation was performed with the biatrial technique described by Lower and Shumway. ${ }^{12}$ Since 1996 we have performed almost all transplants with the bicaval anastomosis technique.

\section{Immunosuppressive Regimen}

All patients received triple immunosuppression consisting of cyclosporine, steroids, and azathioprine. Azathioprine was given at an initial preoperative dose of $4 \mathrm{mg} /(\mathrm{kg} \times \mathrm{d})$, followed by a daily intravenous dose of $2 \mathrm{mg} / \mathrm{kg}$ until the patient could tolerate oral medication. Since 1996 azathioprine has been replaced by mycophenolate mofetil, starting at a dose of $1000 \mathrm{mg}$ twice daily. Cyclosporine was given at the initial dose of 1 to $2 \mathrm{mg} /(\mathrm{kg} \times \mathrm{d})$, which was adjusted to maintain trough whole blood levels between 300 and $350 \mathrm{ng} / \mathrm{dL}$. Between 3 and 6 months after transplantation cyclosporine dosage was adjusted to maintain blood cyclosporine levels between 150 and $250 \mathrm{ng} / \mathrm{dL}$, and after 6 months the levels were kept between 100 and $150 \mathrm{ng} / \mathrm{dL}$. Methylprednisolone (500 $\mathrm{mg}$ ) was administered intravenously during the operation and in the postoperative period at a dose of $125 \mathrm{mg}$ every 8 hours over 24 hours. Prednisone was given in tapering doses from $1 \mathrm{mg} /(\mathrm{kg} \times \mathrm{d})$ immediately after the operation to $0.1 \mathrm{mg} /(\mathrm{kg} \times \mathrm{d})$ by the fourth month. Rejection episodes were treated with oral or intravenous pulses of steroid at $100 \mathrm{mg} / \mathrm{d}$ for 3 days followed by a taper over 1 week to the baseline dose. Patients without response to steroid therapy were treated with cytolytic therapy (OKT3 or ATGAM).

Early in our experience (1992-1996) we noted the development of sensitization in LVAD-supported patients and the subsequent deleterious effects of sensitization. ${ }^{13}$ On the basis of this experience, we devised and subsequently instituted a treatment regimen 
consisting of cyclophosphamide and intravenous immunoglobulin (IVIg) for all sensitized patients from 1997 onward. Twenty-six sensitized LVAD recipients with anti-HLA antibodies awaiting cardiac transplantation received a treatment regimen consisting of 1 to 3 monthly courses of cyclophosphamide given intravenously in a single infusion dose of 0.5 to $1.0 \mathrm{~g} / \mathrm{m}^{2}$ together with pooled human IVIg at $2 \mathrm{~g} / \mathrm{kg}$ given in four divided daily doses. Mesna was intravenously coadministered immediately before and after cyclophosphamide infusion and at the same total dosage to prevent toxic effects of breakdown metabolites on bladder mucosa.

Each sensitized patient received a monthly treatment course consisting of cyclophosphamide and IVIg. Anti-HLA antibody levels were measured at weekly intervals from the date of onset of treatment. Multiple courses $(\leq 3)$ were administered to patients who did not have a significant drop in anti-HLA antibody levels with the initial course. All 26 sensitized cardiac allograft recipients were treated with triple immunosuppression that included monthly posttransplantation pulses of intravenous cyclophosphamide at 0.5 to $1.0 \mathrm{~g} / \mathrm{m}^{2}$ for 4 months instead of mycophenolate mofetil (MMF). These patients subsequently received mycophenolate mofetil for the remainder of the posttransplantation period.

\section{Acute Rejection}

The diagnosis of acute rejection was based on clinical symptoms and confirmed by endomyocardial biopsy performed weekly for the first 3 weeks, every second week for the next three biopsies, every 3 weeks for the next three biopsies, monthly for the first year, and every other month thereafter. The biopsy specimens were graded according to International Society for Heart and Lung Transplantation criteria. ${ }^{14}$ High-grade cellular allograft rejection was defined pathologically as at least grade $3 \mathrm{~A}$ or $3 \mathrm{~B}$.

\section{Angiography and Diagnosis of TCAD}

Patients underwent annual coronary angiography. The diagnosis of TCAD was based on the following criteria: (1) discrete lesions resulting in more than $50 \%$ obstruction of the proximal or mid portions of major graft vessels or (2) diffuse, concentric narrowing of the whole vessels, including their branches. If TCAD was found, the frequency of angiography was increased to a biennial regimen. Patients were not given routine vasodilators before coronary injections. All angiograms were reviewed by a cardiologist and compared with the previous year's films to detect the presence of luminal irregularities, discrete stenoses, loss of third-order branches, or pruning of vessels. Explanted hearts and autopsy specimens were examined for evidence of vessel occlusion and irregularities, ischemic damage, and presence of acute cardiac rejection.

\section{HLA Typing}

Serologic typing of HLA-A and HLA-B loci was performed by standard microcytotoxicity techniques. HLA-DR typing was performed by serologic analysis.

\section{Detection of Anti-HLA Antibodies}

Serum samples were obtained from all patients on the day of transplantation and screened for the presence of lymphocytotoxic antibodies against separated $\mathrm{T}$ lymphocytes and B lymphocytes obtained from a panel of 70 individuals representative of all HLA class I and class II antigens found in the North American population. A negative prospective donor-specific lymphocytic crossmatch was required before transplantation when the anti-HLA antibody reactivity was greater than $20 \%$.

Pretransplantation serum samples were obtained from all patients at risk for sensitization on the day of initial United Network for Organ Sharing listing for transplantation and then every 2 weeks until transplantation. In sensitized patients undergoing treatment, anti-HLA antibody levels were measured at weekly intervals from the date of treatment until transplantation. All sensitized patients, irrespective of whether immunomodulatory therapy was used, underwent a prospective donor specific lymphocytotoxic crossmatch. Posttransplantation serum samples were obtained from all patients with each biopsy.

\section{Determination of Anti-HLA Antibody Specificity for Major Histocompatibility Complex Class I or Class II Antigens}

Working definitions for IgG antibodies against HLA class I molecules or class II molecules were established in our laboratory with serum samples from 28 heart transplant recipients with PRA values greater than $10 \%$ as reference and with anti-HLA class I and class II specificities defined by standard tail analysis as has been described previously elsewhere. ${ }^{13}$

\section{Statistical Analysis}

Differences between groups were examined with the $\chi^{2}$ or Fisher exact test. Continuous variables were compared with a Student $t$ test if values were normally distributed; if not, a Wilcoxon rank sum test was used. Survival estimates were based on the KaplanMeier method, and curves were compared with a log-rank test. ${ }^{15}$ The cumulative rejection frequency used the method of Wei and colleagues $^{16}$ to produce tests and partial likelihood estimates for repeated events. To obtain reliable and comparable relative odds of transplantation for all groups, we arbitrarily chose a period of 2 months (the mean waiting time for status I patients is 2.4 months) and compared probability of transplantation at that time in all studied groups. However, we also studied the mean and median waiting times for transplantation in all these groups for further comparison. Values are reported as mean + SD. Data were analyzed with SAS System software version 6.14 (SAS Institute, Inc, Cary, NC).

\section{Results}

\section{Demographic Characteristics of LVAD Recipients}

One hundred five of 521 heart transplant recipients $(20 \%)$ were supported before transplantation with LVADs. Demographic characteristics of all heart transplant recipients who were bridged with LVADs before heart transplantation and of nonbridged cardiac allograft recipients are shown in Table 1. Sixty seven percent of LVAD recipients (70/105) had a pretransplantation diagnosis of ischemic cardiomyopathy, in contrast to $57 \%$ of nonbridged cardiac allograft recipients $(236 / 416, P=.05)$. Other demographic data did not differ statistically between the two groups. In addition, ischemic time and recipient-donor HLA-A, HLA-B and 
TABLE 1. Comparative statistics between LVAD-bridged and control recipients*

\begin{tabular}{|c|c|c|c|}
\hline & LVAD $(n=105)$ & Control $(n=416)$ & $P$ value \\
\hline Recipient sex (No. female) & $17(17 \%)$ & $97(23 \%)$ & .12 \\
\hline Recipient ethnicity (No. nonwhite) & $21(20 \%)$ & $76(18 \%)$ & .65 \\
\hline Recipient age (y, mean \pm SD) & $50.6 \pm 12.6$ & $51.4 \pm 11.8$ & .56 \\
\hline \multicolumn{4}{|l|}{ Recipient heart diagnosis (No.) } \\
\hline Ischemic heart disease & $70(67 \%)$ & $236(57 \%)$ & .05 \\
\hline Idiopathic cardiomyopathy & $24(23 \%)$ & $107(26 \%)$ & .58 \\
\hline Recipient cytomegalovirus testing (positive/tested) & $52 / 72(72 \%)$ & $227 / 338(67 \%)$ & .40 \\
\hline Ischemic time (min, mean $\pm \mathrm{SD}$ ) & $173 \pm 54$ & $170 \pm 46$ & .50 \\
\hline \multicolumn{4}{|l|}{ Complete mismatch (No.) } \\
\hline HLA-A locus & $68(69 \%)$ & $223(62 \%)$ & .18 \\
\hline HLA-B locus & $83(85 \%)$ & $283(79 \%)$ & .18 \\
\hline HLA-DR locus & $69(70 \%)$ & $231(65 \%)$ & .32 \\
\hline \multicolumn{4}{|l|}{ Initial United Network for Organ Sharing listing (No.) } \\
\hline Status I & $75(77 \%)$ & $104(34 \%)$ & \\
\hline Status II & $22(23 \%)$ & $198(66 \%)$ & $<.001$ \\
\hline
\end{tabular}

*Patients enrolled on United Network for Organ Sharing waiting list between January 1992 and January 1999.

HLA-DR mismatching did not differ between the two groups.

\section{Waiting Times for LVAD Recipients}

As seen in Table 1, most LVAD recipients (77\%) were initially listed as status I patients, in contrast to only $34 \%$ of control recipients $(P<.001)$. Of 97 LVAD recipients who were enrolled on a United Network for Organ Sharing waiting list between January 1992 and January 1999, 53\% (51/97) were listed as status I on the day of LVAD implantation; the remaining $47 \%$ (46/97) were initially listed as either status I $(24 / 46,52 \%)$ or status II $(22 / 46,48 \%)$ and waited a mean duration of $3.9 \pm 7.5$ months (range $0.1-41.8$ months) for LVAD placement and subsequent conversion to status I (Table 2). The mean time from LVAD placement to transplantation was $3.13 \pm 1.7$ months (Table 2).

\section{High Prevalence of Pretransplantation Sensitization to HLA Antigens Among LVAD Recipients}

As shown in Table 3, 66\% of patients receiving LVAD support (69/105) had IgG antibodies directed against HLA molecules develop, compared with only $6 \%$ of nonbridged heart transplant recipients $(24 / 399, P<.001)$. The pretransplantation production of $\mathrm{IgG}$ antibodies was directed against both HLA class I and II molecules; $57 \%$ and $40 \%$ of LVAD recipients had IgG anti-HLA class I and class II antibodies, respectively, in contrast to only $4 \%$ and $4 \%$, respectively, of nonbridged transplant recipients (both $P<.001$ ).

Pretransplantation Sensitization With IgG Anti-HLA Class I Antibodies and Prolonged Waiting Times to Transplantation in LVAD Recipients

Pretransplantation sensitization with IgG anti-HLA antibodies, in particular those directed against class I molecules, prolonged waiting time from LVAD implantation to heart
TABLE 2. Comparison of waiting times between LVADbridged and control recipients*

\begin{tabular}{lcc}
\hline & \multicolumn{2}{c}{ Waiting time (mo) } \\
\cline { 2 - 3 } Waiting period & Mean \pm SD & Median \\
\hline $\begin{array}{l}\text { From listing to LVAD implantation } \\
\quad \text { Status I on day of LVAD implantation } \\
\quad(\mathrm{n}=51)\end{array}$ & 0 & 0 \\
$\quad \begin{array}{l}\text { Enrolled on waiting list before LVAD } \\
\quad \text { placement ( } \mathrm{n}=46)\end{array}$ & $3.90 \pm 7.5$ & 1.3 \\
$\begin{array}{l}\text { From LVAD implantation to transplantation } \\
\text { From listing to transplantation (control) } \\
\quad \text { Status I }\end{array}$ & $3.13 \pm 1.7$ & 3.1 \\
$\quad$ Status II & $1.46 \pm 1.7$ & 0.61 \\
\end{tabular}

*Patients enrolled on United Network for Organ Sharing waiting list between January 1992 and January 1999 only.

TABLE 3. Presence of IgG anti-HLA antibodies before or on the day of transplantation in LVAD-bridged and control recipients

\begin{tabular}{lccc}
\hline & LVAD & Control & $P$ value \\
\hline IgG anti-HLA (I or II) & $69 / 105(66 \%)$ & $24 / 399(6 \%)$ & $<.001$ \\
IgG anti-HLA class I & $60 / 105(57 \%)$ & $17 / 399(4 \%)$ & $<.001$ \\
IgG anti-HLA class II & $43 / 105(40 \%)$ & $15 / 381(4 \%)$ & $<.001$ \\
\hline
\end{tabular}

transplantation. As illustrated in Table 4, the probability of undergoing transplantation was increased 4-fold for LVAD recipients who did not acquire IgG anti-HLA class I antibodies relative to those who did $(P<.0001)$. Of 105 LVAD recipients, only $17 \%$ patients with anti-HLA class I antibodies received a heart transplant within 2 months from LVAD implantation, versus $53 \%$ of control patients $(P<$ .0001. The development of anti-HLA IgG class II antibodies also had an impact on waiting time to transplantation for 
TABLE 4. Pretransplantation sensitization with IgG antiHLA antibodies, in particular directed against class I molecules, and prolonged waiting times to transplantation in LVAD recipients

\begin{tabular}{|c|c|c|c|c|c|}
\hline & \multicolumn{2}{|c|}{$\begin{array}{l}\text { Transplanted } \\
\text { within } 2 \text { mo }\end{array}$} & \multirow{2}{*}{\multicolumn{2}{|c|}{$\begin{array}{c}95 \% \\
\text { Confidence } \\
\text { interval }\end{array}$}} & \multirow[b]{2}{*}{$P$ value } \\
\hline & No. & $\%$ & & & \\
\hline \multicolumn{6}{|c|}{ IgG anti-HLA class I } \\
\hline Sensitized & $10 / 60$ & 17 & 1 & & \\
\hline Control & $24 / 45$ & 53 & 4.219 & $2.014-8.841$ & $<.0001$ \\
\hline \multicolumn{6}{|c|}{ IgG anti-HLA class II } \\
\hline Sensitized & 9/43 & 21 & 1 & 1 & \\
\hline Control & $25 / 62$ & 41 & 2.141 & $0.999-4.590$ & .050 \\
\hline \multicolumn{6}{|c|}{$\begin{array}{l}\text { IgG anti-HLA class I } \\
\text { or II }\end{array}$} \\
\hline Sensitized & $16 / 69$ & 24 & 1 & & \\
\hline Control & $18 / 36$ & 50 & 2.635 & $1.342-5.173$ & .005 \\
\hline
\end{tabular}

LVAD recipients. The probability of transplantation within 2 months of LVAD implantation was 2-fold lower for LVAD recipients who did not acquire anti-HLA class II antibodies $(P=.05)$. For LVAD recipients who acquired antibodies against either class I or II HLA molecules, the probability of undergoing cardiac transplantation was 2.6fold higher than that of control nonsensitized LVAD recipients $(P=.005)$.

Treatment of presensitized $L V A D$ recipients and shortened waiting times to transplantation. Table $5 \mathrm{~A}$ and Table 5B compare the waiting times to transplantation of status I $(\mathrm{n}=104)$ and status II $(\mathrm{n}=201)$ nonsensitized patients with those of sensitized LVAD recipients $(\mathrm{n}=34)$, sensitized untreated LVAD recipients $(n=45)$, and sensitized LVAD recipients who were treated with IVIg and cyclophosphamide $(n=26)$. Relative to status II recipients, the probability of transplantation within 2 months from listing was highest for status I patients (relative risk [RR] 6.160, $P<.001$ ), followed by nonsensitized LVAD recipients (RR 2.7, $P<.001)$ and sensitized LVAD recipients who were treated (RR 2.955, $P<.001$ ). Sensitized LVAD recipients who did not receive any treatment had a likelihood of undergoing transplantation similar to that of status II patients (RR 1.499, $P=.18$ ).

\section{Influence of LVAD Bridging on Recipient Survivals After Heart Transplantation}

As seen in Table 6A, Table 6B, and Figure 1, A, 5-year posttransplantation survival was comparable between LVAD recipients $(75 \%)$ and nonbridged transplant recipients $(72 \%, P=.53)$. Because immunomodulatory regimens for sensitized patients were introduced in 1997 and 1998, a 1-year analysis was thought to be most representative to analyze the impact of immunomodulatory regimens for pretransplantation LVAD sensitization on subsequent posttransplantation survival, as illustrated in Table 6C. One-year mortalities among nonsensitized, nonbridged status I and II patients were $20 \%$ and $17 \%$, respectively; these were not statistically different from the mortalities in LVAD recipients who were not sensitized (18\%), were sensitized and untreated $(16 \%)$, and were sensitized and treated $(12 \%, P=$ $.65)$. Figure $1, B$, presents 5 -year actuarial survivals among these five groups ( $P$ not significant).

\section{Prevention of Increased High-grade Acute Rejection After Cardiac Transplantation in Sensitized LVAD Recipients by IVIg and Cyclophosphamide Therapy} There was no correlation between pretransplantation LVAD support and acute rejection after cardiac transplantation relative to nonbridged cardiac allograft recipients (Figure 2, A). As seen in Table 7A, the incidence of at least one high-grade rejection episode within the first year after cardiac transplantation was $39 \%$ among recipients who had LVADs, versus $37 \%$ among nonbridged cardiac allograft recipients $(\mathrm{RR}=0.93, P=0.71)$. A detailed analysis comparing the five previously described groups of patients, however, supports the hypothesis that transplant recipients with pretransplantation LVAD support were not at an increased risk for acute rejection after heart transplantation unless they were sensitized with anti-HLA antibodies and did not receive any immune intervention. As seen in Figure 2, $B$, and Table 7B, sensitized, untreated LVAD recipients were at 2.7-fold greater risk for at least one high-grade acute rejection within the first posttransplant year than were status I or II patients. In fact, those LVAD recipients who were not sensitized and those who were sensitized and treated had significantly lower cumulative frequencies of rejection $(0.3$ and 0.28 , respectively, $P<.05$ ).

\section{Lack of Association in LVAD Recipients Between} Sensitization and Development of TCAD

There was no association between pretransplantation LVAD support and development of TCAD. The incidence of TCAD among LVAD-supported patients at the first annual angiography (mean duration 18 months after transplantation) was $31 \%$, versus $26 \%$ among control heart transplant recipients (Figure 3, $P=.49$ ). Further, in LVAD recipients pretransplantation sensitization and treatment did not affect the development of TCAD, as shown in Table 8.

\section{Safety Profiles of Pretransplantation and \\ Posttransplantation Immunosuppressive Therapy}

Treatment with intravenously administered cyclophosphamide has proved to be extremely safe. Systemic fungal infections occurred before transplantation in $22 \%$ of sensitized LVAD recipients who did receive cyclophosphamide. The incidence of cytomegalovirus disease (defined as clinical disease together with virologic culture confirmation) 
TABLE 5A. Waiting times from LVAD implantation or enrollment onto a waiting list to heart transplantation*

\begin{tabular}{|c|c|c|c|c|c|c|c|}
\hline & \multicolumn{2}{|c|}{$\begin{array}{l}\text { Transplanted } \\
\text { within } 2 \text { mo }\end{array}$} & \multirow[b]{2}{*}{$\mathbf{R R}$} & \multirow{2}{*}{$\begin{array}{l}\text { 95\% Confidence } \\
\text { interval }\end{array}$} & \multicolumn{2}{|c|}{$\begin{array}{c}\text { Time to transplantation } \\
\text { (mo) }\end{array}$} & \multirow[b]{2}{*}{$P$ value } \\
\hline & No. & $\%$ & & & Median & Mean & \\
\hline Status I $(n=104)$ & 77 & 74 & 6.469 & $4.437-9.432$ & 0.68 & 2.40 & $<.0001$ \\
\hline Status II $(n=201)$ & 43 & 21 & 1 & - & 5.63 & 8.69 & - \\
\hline $\operatorname{LVAD}(\mathrm{n}=105)$ & 47 & 45 & 1.545 & $0.985-2.423$ & 2.51 & 3.01 & .05 \\
\hline
\end{tabular}

*Patients enrolled on United Network for Organ Sharing waiting list between January 1992 and January 1999 only.

TABLE 5B. Waiting times from LVAD implantation or enrollment onto a waiting list to heart transplantation*

\begin{tabular}{|c|c|c|c|c|c|c|c|}
\hline & \multicolumn{2}{|c|}{$\begin{array}{l}\text { Transplanted } \\
\text { within } 2 \text { mo }\end{array}$} & \multirow[b]{2}{*}{ RR } & \multirow{2}{*}{$\begin{array}{l}95 \% \text { Confidence } \\
\text { interval }\end{array}$} & \multicolumn{2}{|c|}{$\begin{array}{c}\text { Time to } \\
\text { transplantation (mo) }\end{array}$} & \multirow[b]{2}{*}{$P$ value } \\
\hline & No. & $\%$ & & & Median & Mean & \\
\hline Status $1(\mathrm{n}=104)$ & 77 & 74 & 6.160 & $4.179-9.078$ & 0.73 & 2.44 & $<.0001$ \\
\hline Status $2(n=201)$ & 43 & 22 & 1 & - & 5.69 & 8.74 & - \\
\hline LVAD not sensitized $(\mathrm{n}=34)$ & 18 & 53 & 2.739 & $1.573-4.768$ & 1.98 & 2.54 & .0004 \\
\hline LVAD sensitized and treated $(n=26)$ & 14 & 54 & 2.955 & $1.610-5.424$ & 1.70 & 2.48 & .0005 \\
\hline LVAD sensitized $(n=45)$ & 15 & 33 & 1.499 & $0.830-2.708$ & 2.83 & 3.66 & .179 \\
\hline
\end{tabular}

*Patients enrolled on United Network for Organ Sharing waiting list between January 1992 and January 1999 only.

TABLE 6A. Influence of LVAD bridging on survival after heart transplantation

\begin{tabular}{|c|c|c|c|c|c|}
\hline & \multicolumn{2}{|c|}{$\begin{array}{c}\text { Survival } \\
5 \text { y after } \\
\text { transplantation }\end{array}$} & \multirow[b]{2}{*}{$\mathbf{R R}$} & \multirow{2}{*}{$\begin{array}{c}95 \% \\
\text { Confidence } \\
\text { interval } \\
\end{array}$} & \multirow[b]{2}{*}{$P$ value } \\
\hline & No. & $\%$ & & & \\
\hline Status $I^{*}(n=104)$ & 71 & 68 & 1.469 & $0.941-2.293$ & .06 \\
\hline Status II* $(n=201)$ & 154 & 77 & 1 & - & - \\
\hline $\operatorname{LVAD}(\mathrm{n}=105)$ & 79 & 75 & 1.056 & $0.576-1.588$ & .86 \\
\hline
\end{tabular}

*Patients enrolled on United Network for Organ Sharing waiting list between January 1992 and January 1999 only.

TABLE 6B. Influence of LVAD bridging on survival after heart transplantation

\begin{tabular}{|c|c|c|c|c|c|}
\hline & \multicolumn{2}{|c|}{$\begin{array}{c}\text { Survival } \\
5 \text { y after } \\
\text { transplantation }\end{array}$} & \multirow{2}{*}{\multicolumn{2}{|c|}{$\begin{array}{c}95 \% \\
\text { Confidence } \\
\text { interval }\end{array}$}} & \multirow[b]{2}{*}{$P$ value } \\
\hline & No. & $\%$ & & & \\
\hline $\operatorname{LVAD}(\mathrm{n}=105)$ & 79 & 75 & 0.862 & $0.543-1.367$ & .53 \\
\hline Control $(n=416)$ & 300 & 72 & 1 & - & - \\
\hline
\end{tabular}

after transplantation was 3 of 26 cyclophosphamide-treated patients (12\%). No other systemic viral, bacterial, or fungal infections were seen in patients treated with cyclophosphamide. Cyclophosphamide therapy was frequently $(>80 \%)$ accompanied by transient nausea and vomiting that responded to antiemetic therapy. Mesna was coadministered with cyclophosphamide and may have contributed to the
TABLE 6C. Influence of LVAD bridging on survival after heart transplantation

\begin{tabular}{lcccc}
\hline & $\begin{array}{c}\text { 1-y } \\
\text { mortality }\end{array}$ & RR & $\begin{array}{c}\mathbf{9 5 \%} \\
\text { Confidence } \\
\text { interval }\end{array}$ & $\boldsymbol{P}$ value \\
\hline Status 1* & $20 \%$ & 1.762 & $0.521-5.955$ & .36 \\
Status 2* & $17 \%$ & 1 & - & - \\
LVAD not sensitized & $18 \%$ & 1.553 & $0.388-6.211$ & .53 \\
LVAD sensitized & $16 \%$ & 1.314 & $0.340-5.083$ & .69 \\
LVAD sensitized and & $12 \%$ & 1.283 & $0.453-4.852$ & .51 \\
$\quad$ treated & & & & \\
\hline
\end{tabular}

*Patients enrolled on United Network for Organ Sharing waiting list between January 1992 and January 1999 only.

absence of any cases of hemorrhagic cystitis. No malignancies have developed after 53.5 patient-mo of follow-up (range 6-38 months). IVIg therapy was associated with immune complex disease in 4 of 26 monthly courses (15\%), as evidenced by fevers, arthralgias, and maculopapular rashes. Reversible renal insufficiency (defined as $>50 \%$ increase in serum creatinine level) occurred in 4 cases.

\section{Discussion}

Historically, it was Medawar ${ }^{17}$ in 1946 who first described the accelerated pace of skin graft rejection in rabbits challenged with donor blood relative to the process of acute rejection in unsensitized animals. Later, Simonsen and associates ${ }^{18}$ showed that a second transplant from the original canine donor and not from a third-party donor was rejected faster than was the first organ. It was shown more than 30 

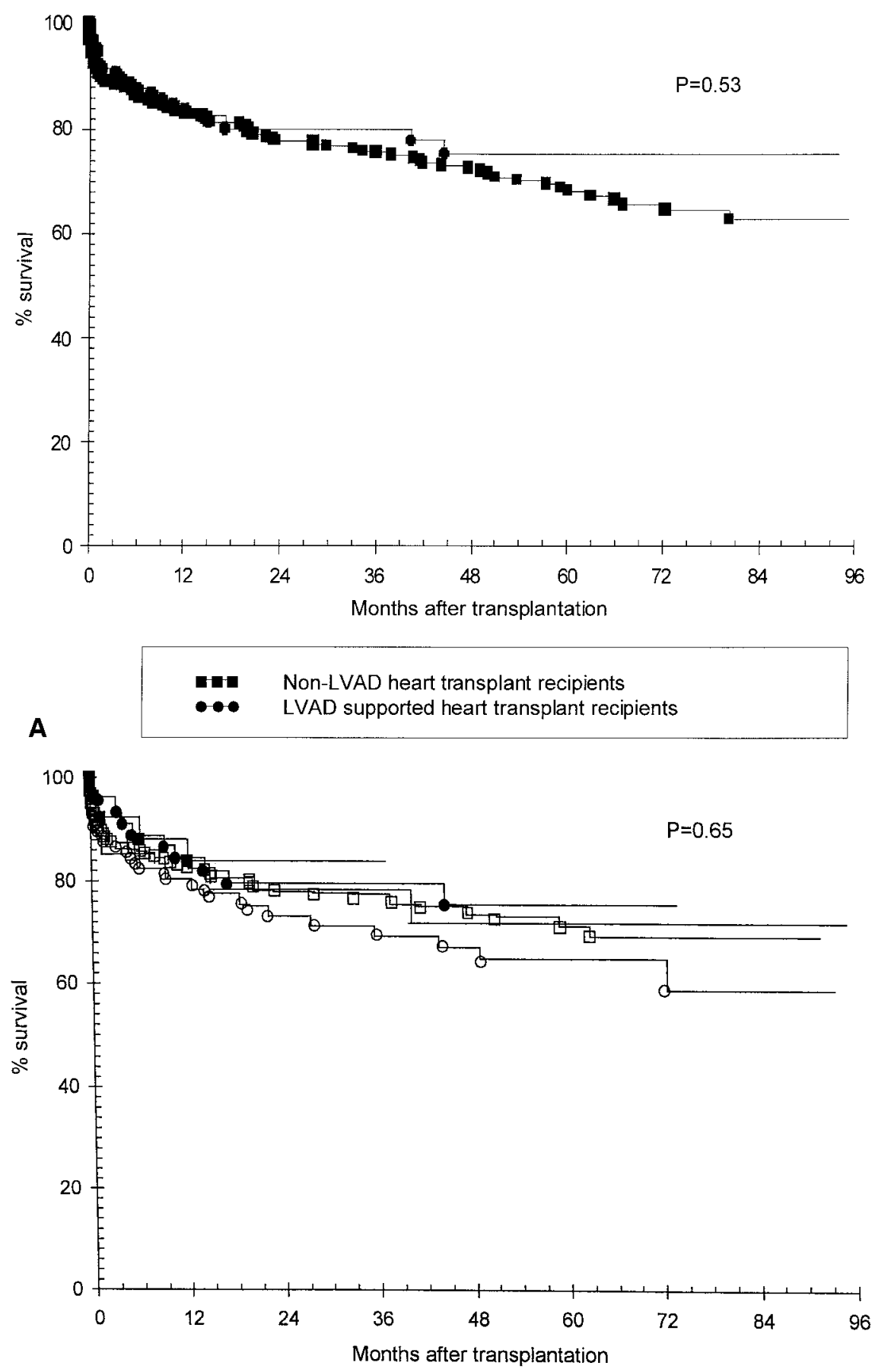

B

-1. LVAD not sensitized

4A LVAD sensitized treated

- LVAD sensitized not treated

000 Status I recipients non sensitized

$\square \square \square \quad$ Status II recipients non sensitized

Figure 1. Actuarial (Kaplan-Meier) survivals after heart transplantation. Symbols represent actual events, positioned along horizontal axis at time of event and by Kaplan-Meier method along vertical axis. A, Squares, Nonbridged recipients; triangles, LVAD-bridged recipients. B, Filled squares, Sensitized and treated LVAD recipients; triangles, unsensitized LVAD recipients; filled circles, sensitized untreated LVAD recipients; open circles, status I recipients; open squares, unsensitized status II recipients. 

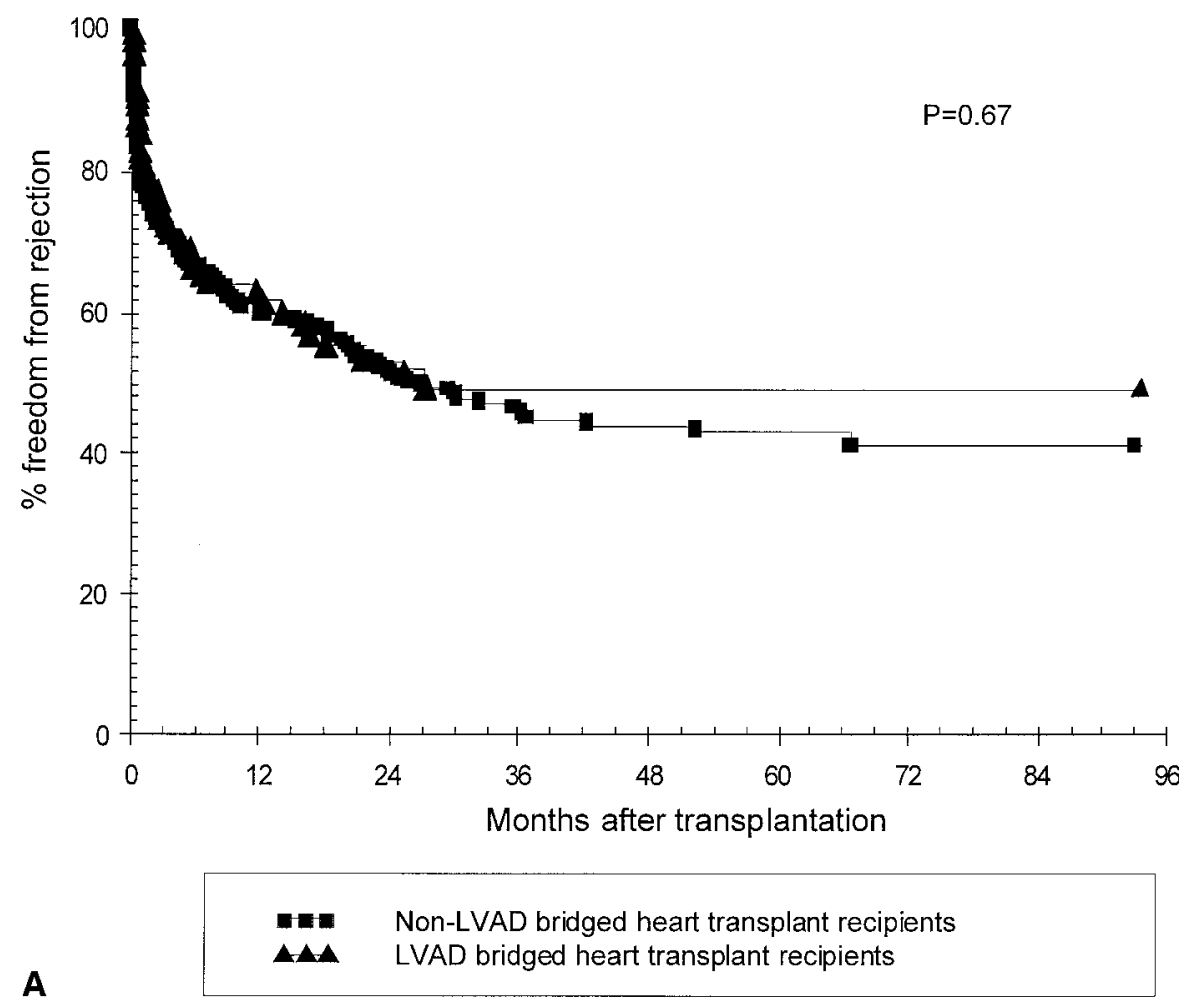

A

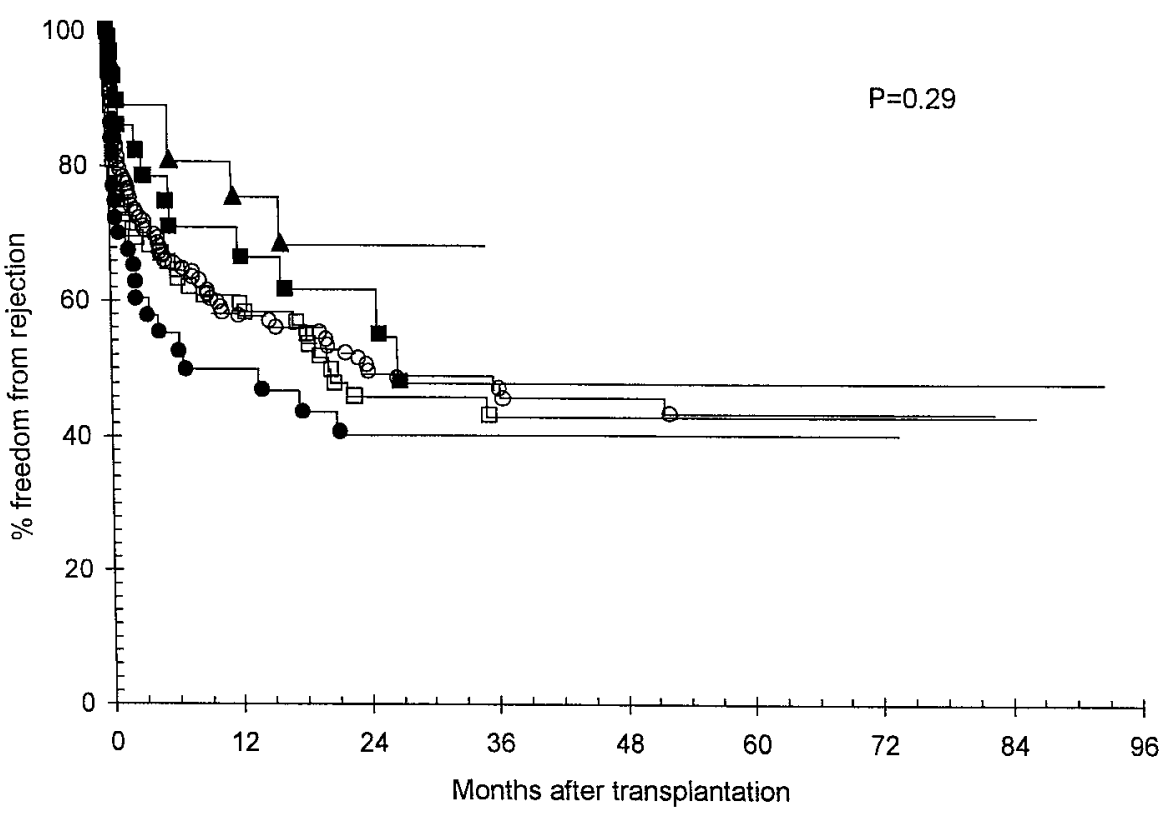

B
LVAD not sensitized
$\rightarrow$ LVAD sensitized treated
$\cdots \quad$ LVAD sensitized not treated
000 Status I recipients non sensitized
$\square \square \square \quad$ Status II recipients non sensitized

Figure 2. Actuarial (Kaplan-Meier) freedoms from high-grade acute rejection. Symbols represent actual events, positioned along horizontal axis at time of event and by Kaplan-Meier method along vertical axis. A, Squares, Nonbridged recipients; triangles, LVAD-bridged recipients. B, Filled squares, Unsensitized LVAD recipients; triangles, sensitized and treated LVAD recipients; filled circles, sensitized untreated LVAD recipients; open circles, status I recipients; open squares, status II recipients. 
TABLE 7A. Influence of LVAD bridging on acute rejection after heart transplantation*

\begin{tabular}{|c|c|c|c|c|c|c|c|}
\hline & & & Rejectic & $12 \mathrm{mo}$ & & Frequency & \\
\hline & No. & $\%$ & RR & $\begin{array}{l}\text { 95\% Confidence } \\
\text { interval }\end{array}$ & $P$ value & $\begin{array}{c}\text { rejection at } \\
12 \mathrm{mo}\end{array}$ & $P$ value \\
\hline $\operatorname{LVAD}(\mathrm{n}=105)$ & $40 / 103$ & 39 & 1 & - & - & 0.45 & - \\
\hline Control $(n=416)$ & $142 / 383$ & 37 & 0.933 & $0.641-1.356$ & .71 & 0.53 & .31 \\
\hline
\end{tabular}

*Patients enrolled on United Network for Organ Sharing waiting list between January 1992 and January 1999 only.

TABLE 7B. Influence of LVAD bridging on acute rejection after heart transplantation*

\begin{tabular}{|c|c|c|c|c|c|c|c|}
\hline & \multicolumn{5}{|c|}{ Rejection within 12 mo } & \multirow{2}{*}{$\begin{array}{c}\text { Frequency of } \\
\text { rejection at } \\
12 \mathrm{mo}\end{array}$} & \multirow[b]{2}{*}{$P$ value } \\
\hline & No. & $\%$ & RR & $\begin{array}{l}95 \% \text { Confidence } \\
\text { interval }\end{array}$ & $P$ value & & \\
\hline Status 1 not sensitized $(\mathrm{n}=89$ ) & 34 & 39 & 1.949 & $0.762-4.983$ & .16 & 0.54 & .45 \\
\hline Status 2 not sensitized ( $\mathrm{n}=175)$ & 70 & 40 & 2.002 & $0.808-4.960$ & .14 & 0.62 & - \\
\hline LVAD not sensitized ( $\mathrm{n}=33$ ) & 9 & 27 & 1.261 & $0.413-3.856$ & .68 & 0.3 & .05 \\
\hline LVAD sensitized and treated $(n=26)$ & 6 & 22 & 1 & - & - & 0.28 & .03 \\
\hline LVAD sensitized $(n=44)$ & 25 & 48 & 2.732 & $1.030-7.247$ & .04 & 0.63 & .93 \\
\hline
\end{tabular}

*Patients enrolled on United Network for Organ Sharing waiting list between January 1992 and January 1999 only.

years ago that human renal allografts in sensitized recipients may undergo fulminant rejection within minutes or hours after revascularization. ${ }^{3}$ Because of the historic concept that rejection in sensitized individuals is driven primarily by the humoral component of the host immune system, cellular immune responses have received relatively less attention. However, current concepts emphasize the interdependence of the two pathways and recognize a key role for $\mathrm{T}$ cells, primarily of the CD4 phenotype, and macrophages in the initiation and control of B-cell differentiation and immunoglobulin production through the elaboration of a number of cytokine mediators.

As mentioned earlier, the classic risk factors for alloimmunization in organ transplant recipients, including previous allografts, pregnancy, and blood transfusions, have been extensively studied in renal allograft recipients. More recently, sensitization in patients awaiting cardiac transplantation has been of significant importance and has been evaluated in detail. Our current experience shows that $66 \%$ of patients receiving LVAD support acquired IgG antibodies directed against HLA molecules, versus only $6 \%$ of nonbridged heart transplant recipients. In an earlier analysis of 40 patients receiving LVAD support while awaiting cardiac transplantation at our institution, Moazami and colleagues ${ }^{19}$ observed that $80 \%$ of patients had development of antibodies against major histocompatibility complex class I or II antigen. Several risk factors, including previous pregnancy, transfusions, age, sex, concurrent risk factors, and perioperative blood product use, were studied in an attempt to predict risk factors for the development of these antibodies. According to multivariate analysis, only platelet transfusions were predictive of development of anti-HLA IgG antibodies, with patients receiving more than 6 units of platelets being at higher risk. However, the significance of the importance of blood products in sensitization in patients with heart failure receiving LVAD support while awaiting cardiac transplantation is controversial. Stringham and colleagues ${ }^{20}$ used a strict protocol to avoid transfusion of cellular blood products to LVAD recipients and concluded that this did not universally protect these patients against HLA allosensitization. They suggested that the use of freshfrozen plasma (which could contain small amounts of soluble HLA antigens) and that previous cardiac surgery could themselves influence sensitization. Massad and coworkers ${ }^{2}$ showed that there was no significant difference in the frequency of HLA sensitization between LVAD recipients tested before LVAD support and nonbridged patients tested before cardiac transplantation; however, sensitization was present in $66 \%$ of all patients tested after LVAD placement. Further, a significant increase in mean PRA level occurred during LVAD support. The influence of infections on sensitization in patients receiving mechanical circulatory support is also controversial. ${ }^{21,22}$

It is also possible that the immunologic alterations in recipients with LVADs may be directly related to interactions between the LVAD surface and the host immune system itself. We have shown that TCI LVAD implantation (Thermo Cardiosystems, Inc, Woburn, Mass) is accompanied by colonization of the LVAD surface with heterogeneous cellular populations composed primarily of monocytes or macrophages and T cells. ${ }^{10}$ Detailed examination of the T-cell populations on the LVAD surface demonstrated heightened in vivo $T$-cell activation of both $\mathrm{T}_{\mathrm{H}} 1$ and $\mathrm{T}_{\mathrm{H}} 2$ type cells, as determined by markers of cellular activation 


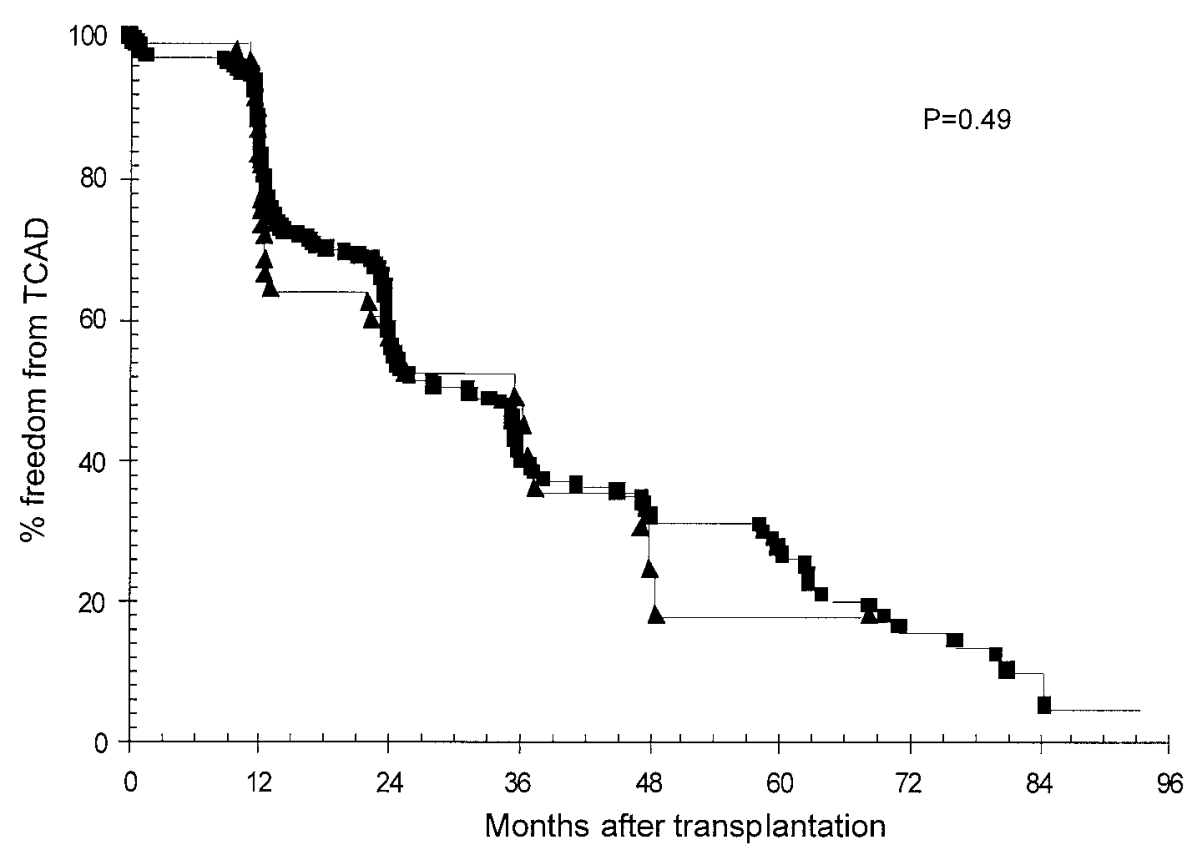

Non-LVAD bridged heart transplant recipients

LAAD bridged heart transplant recipients

Figure 3. Actuarial (Kaplan-Meier) freedoms from TCAD detected by annual coronary angiography. Symbols represent actual events, positioned along horizontal axis at time of event and by Kaplan-Meier method along vertical axis. Squares, Nonbridged recipients; triangles, LVAD-bridged recipients.

TABLE 8A. Influence of LVAD bridging on TCAD after heart transplantation

\begin{tabular}{|c|c|c|c|c|c|}
\hline & \multicolumn{2}{|c|}{$\begin{array}{c}\text { Positive } \\
\text { first annual } \\
\text { angiogram }\end{array}$} & \multirow[b]{2}{*}{ RR } & \multirow{2}{*}{$\begin{array}{c}95 \% \\
\text { Confidence } \\
\text { interval }\end{array}$} & \multirow[b]{2}{*}{$P$ value } \\
\hline & No. & $\%$ & & & \\
\hline LVAD & $28 / 87$ & 31 & 1.355 & $0.828-2.217$ & .27 \\
\hline Control & $89 / 351$ & 26 & 1 & - & - \\
\hline
\end{tabular}

and cytokine messenger RNA gene expression. As a result of this heightened state of activation after exposure to the LVAD surface, circulating $\mathrm{T}$ cells in LVAD recipients demonstrated excessive T-cell apoptosis through CD95CD95L interactions, with a concomitant increase in production of $\mathrm{T}_{\mathrm{H}} 2$ cytokines, particularly interleukin 10 . Because augmented levels of CD95-dependent T-cell apoptosis ${ }^{23,24}$ and a predominant $\mathrm{T}_{\mathrm{H}} 2$ type cytokine profile 25,26 are features also common to patients with systemic lupus erythematosus, LVAD implantation may serve as an iatrogenic model for diseases of B-cell hyperreactivity and autoantibody production.

The clinical implications of sensitization in LVAD recipients awaiting cardiac transplantation are significantly
TABLE 8B. Influence of LVAD bridging on TCAD after heart transplantation

\begin{tabular}{|c|c|c|c|c|c|}
\hline & \multicolumn{2}{|c|}{$\begin{array}{c}\text { Positive } \\
\text { first annual } \\
\text { angiogram }\end{array}$} & \multirow[b]{2}{*}{ RR } & \multirow{2}{*}{$\begin{array}{c}95 \% \\
\text { Confidence } \\
\text { interval }\end{array}$} & \multirow[b]{2}{*}{$P$ value } \\
\hline & No. & $\%$ & & & \\
\hline Status $1^{*}$ & $22 / 75$ & 29 & 0.983 & $0.289-3.338$ & .977 \\
\hline Status $2^{*}$ & $64 / 180$ & 34 & 1 & - & - \\
\hline LVAD not sensitized & $9 / 27$ & 30 & 0.846 & $0.260-2.751$ & .781 \\
\hline $\begin{array}{l}\text { LVAD sensitized } \\
\text { and treated }\end{array}$ & $5 / 20$ & 25 & 0.962 & $0.241-3.850$ & .967 \\
\hline LVAD sensitized & $14 / 39$ & 36 & 1.199 & $0.338-4.251$ & .977 \\
\hline
\end{tabular}

*Patients enrolled on United Network for Organ Sharing waiting list between January 1992 and January 1999 only.

adverse in nature. The presence of preformed anti-HLA alloantibodies in serum samples of patients awaiting cardiac transplantation predicts a high likelihood of repeated positive donor-specific T-cell crossmatch reactivity, with the consequence of increased waiting time to transplantation. The complications of long-term LVAD use, together with the effects of the underlying cardiac disease state, make such prolongation of the waiting time to transplantation a 
significant risk factor for morbidity and mortality among patients on cardiac transplant waiting lists.

Only approximately $35 \%$ of patients in the United States awaiting cardiac transplantation receive transplants during a given year, whereas nearly $30 \%$ die awaiting a suitable donor. The likelihood of transplantation is even lower for highly sensitized patients with high levels of circulating anti-HLA antibodies. Much of the data on sensitized patients has emerged from extensive experience with renal transplant recipients. Potential primary or reoperative renal transplant candidates with high levels of these antibodies are subject to prolonged waiting periods for a transplant. On the basis of the experience in renal transplantation, potential cardiac allograft recipients with PRA levels greater than $20 \%$ require a negative prospective (before transplantation) donor-specific lymphocytotoxic crossmatch to receive the organ. Thus individuals whose serum samples repeatedly yield positive crossmatch reactions have longer waiting times until a crossmatch-negative donor can be found. Although successful heart transplantation in sensitized patients without a prospective crossmatch has been reported, it has been our strict policy to perform a prospective donor specific crossmatch in sensitized patients. This obviously precludes distant organ procurement for these patients, thereby narrowing an already shrunken donor pool. Unlike the case of renal transplant recipients, who can be successfully maintained with dialysis for prolonged periods, the lack of a widely available reliable alternative cardiac support system (with the exception of LVADs until recently) translates prolongation of waiting time into clinical deterioration and sometimes death. As a result, it has been the policy of some transplant centers to perform only retrospective crossmatches for cardiac transplant recipients. Our experience demonstrates that the probability of undergoing transplantation was increased by 4-fold in LVAD recipients who do not acquire $\mathrm{IgG}$ anti-HLA class I antibodies relative to LVAD recipients with IgG anti-HLA class I antibodies. The development of antiHLA class II antibodies also had an impact, although less significant than that of class I antibodies, on waiting times to transplantation in LVAD recipients.

We have shown that the presence of anti-IgG class II antigens at the time of cardiac transplantation was highly predictive of early high-grade cellular rejection as well as of higher cumulative annual rejection frequency in the posttransplantation period. ${ }^{13}$ Acute cellular rejection of cardiac allografts is accompanied both in the circulation and in the allograft of recipient $\mathrm{T}$ cells that react with donor HLA-DR peptides presented by self-antigen-presenting cells. ${ }^{27}$ The relationship between recurrent high-grade cellular rejections and preexisting IgG anti-class II antibodies may be related to the presence of circulating presensitized memory B cells in allosensitized patients that are capable of reacting with HLA-DR molecules and presenting cryptic epitopes to helper CD4 T cells. ${ }^{28,29}$ More importantly, we have shown that immunomodulatory therapy reduced the prolonged waiting time as well as the increased risk for acute rejection in highly sensitized patients.

Immunologic treatment of sensitized LVAD recipients before transplantation with intravenously administered cyclophosphamide together with IVIg significantly reduced serum alloreactivity, ${ }^{30}$ also reducing waiting list times to those of nonsensitized patients. The mechanism by which IVIg transiently reduces anti-HLA serum reactivity is not well defined but may be related to the presence in the IVIg preparation of soluble HLA class I molecules that bind circulating anti-HLA antibodies ${ }^{31,32}$ or of non-complement-fixing antibodies against HLA class I molecules that compete with recipient alloreactive antibodies by binding to nonpolymorphic determinants in the $\alpha$-helical region of HLA class I molecules. ${ }^{33}$ Although IVIg stimulates the production of immunoglobulin $\mathrm{M}$ anti-idiotypic blocking antibodies to HLA in recipient serum, ${ }^{34}$ this immunomodulatory mechanism is unlikely to account for the rapid, transient, and nonsustained clinical effect observed with IVIg administration. IVIg therapy has been used with considerable success in the treatment of highly sensitized patients awaiting kidney transplantation..$^{35}$ Glotz and associates ${ }^{36}$ reported on the use of high-dose IVIg therapy in highly sensitized patients receiving dialysis treatment to allow decrease in HLA-specific alloantibodies. Cyclophosphamide administered long term in low doses has been used with increasing success in the treatment of several autoimmune diseases that are characterized by hyperactivity of the immune system. ${ }^{37}$ Because the mode of action of cyclophosphamide involves antimitotic mechanisms, it is most effective when used against B cells that are rapidly proliferating. Although immunoglobulin production may be augmented shortly after initiation of cyclophosphamide therapy, B-cell function is suppressed by long-term low-dose therapy. Cyclophosphamide therapy has also been shown to have a selective suppressive effect on discrete stages of the B-cell cycle, including both proliferation and differentiation. ${ }^{38}$

Rose and coworkers ${ }^{39}$ reported an association between anti-HLA antibodies and accelerated coronary artery disease in cardiac allograft recipients. In a large retrospective study of 463 cardiac allograft recipients, Lavee and cowork$\mathrm{ers}^{7}$ showed that the degree of PRA elevation correlated not only with the occurrence of early acute rejection but also with subsequent development of graft atherosclerosis. Thus these studies suggested an association between the presence of anti-HLA antibody and accelerated graft atherosclerosis. However, direct histopathologic examination of the cardiac allograft has not demonstrated a primary role for alloantibody in graft disease..$^{40}$ The definitive role of cell-mediated immune responses probably leaves a complementary role 
for alloantibody in graft atherosclerosis, possibly by enhancing T-cell binding to the vascular endothelium. We did not find an association between the presence of preformed anti-HLA antibodies and the development of TCAD. It is possible that the current immunosuppressive regimens, the improved detection and treatment of acute rejection, and prophylaxis for cytomegalovirus infections have reduced the impact of preformed antibodies on TCAD development.

In conclusion, because the frequency of HLA sensitization has shown to be increased among LVAD recipients it is especially important that PRA testing be performed at regular intervals for LVAD recipients awaiting cardiac transplantation. Before transplantation all patients with elevated PRA levels $(>20 \%)$ should undergo prospective lymphocytotoxic crossmatching with donor T- and B-lymphocytes with determination of $\mathrm{IgG}$ and immunoglobulin $\mathrm{M}$ specificities. Because of the current time constraints on cold ischemic time of heart preservation, it is not feasible to perform prospective crossmatching for every cardiac transplant recipient. A positive $\operatorname{IgG}$ lymphocytotoxic crossmatch against donor $\mathrm{T}$ lymphocytes should be a definite contraindication for heart transplantation. It has been suggested that patients who are highly sensitized before transplantation may be at risk for the development of anti-HLA antibodies in the posttransplantation period, thereby potentially contributing to deleterious effects on the cardiac allograft. Thus these patients merit close follow up and possibly even more intense and targeted immunosuppression. Further studies are required to assess the role of more selective and less global immunosuppression in this group of sensitized patients. With increasing use of LVADs for patients with heart failure, a better understanding of their immunologic interactions and their subsequent clinical consequences is essential to achieve continued successful outcomes fir patients with end-stage heart failure. ${ }^{41,42}$

\section{References}

1. Braun WE. Laboratory and clinical management of the highly sensitized organ transplant recipient. Hum Immunol. 1989;26:245-60.

2. Massad MG, Cook DJ, Schmitt SK, Smedira NG, McCarthy JF, Vargo $\mathrm{RL}$, et al. Factors influencing HLA sensitization in implantable LVAD recipients. Ann Thorac Surg. 1997;64:1120-5.

3. Kissmeyer-Nielsen F, Olsen S, Petersen VP, Fjeldborg O. Hyperacute rejection of kidney allografts associated with pre-existing humoral antibodies against donor cells. Lancet. 1966;2:662-5.

4. Patel R, Terasaki PI. Significance of the positive crossmatch test in kidney transplantation. N Engl J Med. 1969;14:735-9.

5. Smith, JD, Danskine, AJ, Laylor, RM, Rose, ML, Yacoub, MH. The effect of panel reactive antibodies and the donor specific crossmatch on graft survival after heart and heart-lung transplantation. Transpl Immunol. 1993;1:60-5.

6. Ratkovec RM, Hammond EH, O'Connell JB, Bristow MR, DeWitt $\mathrm{CW}$, Richenbacher WE, et al. Outcome of cardiac transplant recipients with a positive donor-specific crossmatch-preliminary results with plasmapheresis. Transplantation. 1992;54:651-5.

7. Lavee J, Kormos RL, Duquesnoy RJ, Zerbe TR, Armitage JM, Vanek $\mathrm{M}$, et al. Influence of panel-reactive antibody and lymphocytotoxic cross-match on survival after heart transplantation. J Heart Lung Transplant. 1991;10:921-30.

8. John R, Rajasinghe HA, Chen JM, Weinberg AD, Sinha P, Itescu S, et al. Impact of current management practices on early and late mortality in over 500 consecutive heart transplant recipients. Ann Surg. 2000;232:302-11.

9. John R, Chen JM, Weinberg A, Oz MC, Mancini D, Itescu S, et al. Long-term survival after cardiac retransplantation: a twenty-year single-center experience. J Thorac Cardiovasc Surg. 1999;117:543-55.

10. Ankersmit J, Tugulea S, Spanier T, Burke E, Flannery M, Weinberg A, et al. Activation-induced T cell death (AICD) and immune dysfunction after left ventricular assist device (LVAD) implantation. Lancet. 1999;354:550-6.

11. Schuster M, Kocher A, John R, Hoffman M, Ankersmit J, Lietz K, et al. B cell activation and allosensitization after left ventricular assist device implantation is due to $\mathrm{T}$ cell activation and CD40 ligand expression. Hum Immunol. 2002;63:211-20.

12. Lower RR, Shumway NE. Studies of orthotopic cardiac homotransplantations of the canine heart. Surg Forum. 1960;11:18-9.

13. Itescu S, Tung T, Burke E, Weinberg A, Oz M, Suciu-Foca N, et al. Preformed IgG antibodies against major histocompatibility class II antigens are major risk factors for high-grade cellular rejection in recipients of heart transplantation. Circulation. 1998;98:786-93.

14. Billingham ME, Cary NR, Hammond ME, Kemnitz J, Marboe C, McCallister HA, et al. A working formulation for the standardization of nomenclature in the diagnosis of heart and lung rejection: Heart Rejection Study Group. J Heart Lung Transplant. 1990;9:587-93.

15. Kaplan EL, Meier P. Nonparametric estimation from incomplete observations. J Am Stat Assoc. 1958;53:457.

16. Wei LJ, Lin DY, Weissfeld L. Regression analysis of multivariate incomplete failure time data by modeling marginal distributions. $J \mathrm{Am}$ Stat Assoc. 1989;84:1065.

17. Medawar PB. Immunity to homologous grafted skin: II. The relationship between the antigens of blood and skin. Br J Exp Pathol. 1946;27:15-24.

18. Simonsen M, Buemann J, Grammeltoft A, Jensen F, Jorgensen K. Biological incompatibility in dogs. I. Experimental and morphological investigations. Acta Pathol Microbiol Scand. 1953;32:1-35.

19. Moazami N, Itescu S, Williams M, Argenziano M, Weinberg A, Oz M. Platelet transfusions are associated with the development of antimajor histocompatibility complex class I antibodies in patients with left ventricular assist support. J Heart Lung Transplant. 1998;17:87680.

20. Stringham JC, Bull DA, Fuller TC, Kfoury AG, Taylor DO, Renlund $\mathrm{DG}$, et al. Avoidance of cellular blood product transfusions in LVAD recipients does not prevent HLA allosensitization. J Heart Lung Transplant. 1999;18:160-5.

21. Holmann WL, Skinner JL, Waites KB, Benzer RC, McGiffin DC, Kirklin JK. Infections during circulatory support with ventricular assist devices. Ann Thorac Surg. 1999;68:1080-2.

22. McCarthy PM, Schmitt SK, Vargo RL, Gordon S, Keys TF, Hobbs RE, et al. Implantable LVAD infections: implications for permanent use of the device. Ann Thorac Surg. 1996;61:359-65.

23. Perniok A, Wedekind F, Herrmann M, Specker C, Schneider M. High levels of circulating early apoptotic peripheral blood mononuclear cells in systemic lupus erythematosus. Lupus. 1998;7:113-8.

24. Cameron PU, Pope M, Gezelter S, Steinman RM. Infection and apoptotic cell death of $\mathrm{CD} 4+\mathrm{T}$ cells during an immune response to HIV-1-pulsed dendritic cells. AIDS Res Human Retroviruses. 1994; 10:61-71.

25. Funauchi M, Ikoma S, Enomoto H, Horiuchi A. Decreased Th1-like and increased Th2-like cells in systemic lupus erythematosus. Scand J Rheumatol. 1998,27:219-24.

26. Horwitz DA, Gray JD, Behrendsen SC, Kubin M, Rengaraju M, Ohtsuka K, et al. Decreased production of interleukin 12 and other Th1-type cytokines in patients with recent-onset systemic lupus erythematosus. Arthritis Rheum. 1998;41:838-44.

27. Liu Z, Colovai AI, Tuglea S, Reed E, Fisher PE, Mancini D, et al. Indirect recognition of donor HLA-DR peptides in organ allograft rejection. J Clin Invest. 1996;98:1150-7. 
28. Ciubotariu R, Liu Z, Colovai AI, Ho E, Itescu S, Ravalli S, et al. Persistent allopeptide reactivity and epitope spreading in chronic rejection of organ allografts. J Clin Invest. 1998;101:398-405.

29. Vanderlugt CJ, Miller SD. Epitope spreading. Curr Opin Immunol. 1996;8:831-6.

30. John R, Lietz K, Burke E, Ankersmit J, Mancini D, Suciu-Focca N, et al. Intravenous immunoglobulin reduces anti-HLA alloreactivity and shortens waiting time to cardiac transplantation in highly sensitized left ventricular assist device recipients. Circulation. 1999;100(19 Suppl):II229-35.

31. Kaveri S, Vassilev T, Hurez V, Lengagne R, Lefranc C, Cot S, et al. Antibodies to a conserved region of HLA class I molecules, capable of modulating CD8 T cell-mediated function, are present in pooled normal immunoglobulin for therapeutic use. J Clin Invest. 1996;97: 865-9.

32. Dammacco F, Iodice G, Campobasso N. Treatment of adult patients with idiopathic thrombocytopenic purpura with intravenous immunoglobulin: effects on circulating $\mathrm{T}$ cell subsets and PWM-induced antibody synthesis in vitro. Br J Haematol. 1986;62:125-35.

33. Toungouz M, Denys C, Dupont E. Blockade of proliferation and tumor necrosis factor- $\alpha$ production occurring during mixed lymphocyte reaction by interferon-gamma-specific natural antibodies contained in intravenous immunoglobulins. Transplantation. 1996;62: 1292-6.

34. Reed E, Hardy M, Benvenisty A, Lalter C, Brensilver J, McCabe R, et al. Effect of antiidiotypic antibody to HLA on graft survival in renal allograft recipients. $N$ Engl J Med. 1987;316:1450-5.

35. Tyan DB, Li VA, Czer L, Trento A, Jordan SC. Intravenous immunoglobulin suppression of HLA alloantibody in highly sensitized transplant candidates and transplantation with a histoincompatible organ. Transplantation. 1994;57:553-62.

36. Glotz D, Haymann J, Sansonetti N, Francois A, Menoyo-Calonge V, Bariety J. Suppression of HLA-specific alloantibodies by high-dose intravenous immunoglobulins (IVIg). Transplantation. 1993;56:3357.

37. Belmont HM, Storch M, Buyon J, Abramson S. New York University/ Hospital for Joint Diseases experience with intravenous cyclophosphamide treatment: efficacy in steroid unresponsive lupus nephritis. Lupus. 1995;4:104-8.

38. Zhu L, Cupps TR, Whalen G, Fauci AS. Selective effects of cyclophosphamide therapy on activation, proliferation and differentiation of human B cells. J Clin Invest. 1987;79:1082-90.

39. Rose EA, Smith CR, Petrossian GA, Barr ML, Reemtsma K. Humoral immune responses after cardiac transplantation: correlation with fatal rejection and graft atherosclerosis. Surgery. 1989;106:203-8.

40. Hess ML, Hastillo A, Mohanakumar T, Cowley MJ, Vetrovac G, Szentpetery S, et al. Accelerated atherosclerosis in cardiac transplantation: role of cytotoxic B-cell antibodies and hyperlipidemia. Circulation. 1983;68:94-101.

41. Oz MC, Argenziano M, Catanese KA, Gardocki MT, Goldstein DJ, Ashton RC, et al. Bridge experience with long-term implantable left ventricular assist devices. Are they an alternative to transplantation? Circulation. 1997;95:1844-52.

42. Rose EA, Gelijns AC, Moskowitz AJ, Heitjan DF, Stevenson LW, Dembitsky W, et al. Long-term use of a left ventricular assist device for end-stage heart failure. N Engl J Med. 2001;345:1435-43.

\section{Discussion}

Dr Anees J. Razzouk (Loma Linda, Calif). The limited supply of donor organs has caused an increase in the use of mechanical circulatory support to bridge potential recipients to cardiac transplantation. Allosensitization to HLA class I or II antigens, defined as PRA greater than $10 \%$, can develop during LVAD support and has become a clinical problem of significance. Concerns regarding the adverse effects of sensitization on graft rejection and recipient survival have prompted different therapies to reduce PRA before transplantation. Such regimens have included plasmapheresis, avoidance of cellular blood product transfusions in LVAD recip- ients, administration of IVIg, and immunosuppression. There is significant controversy with regard to the management of sensitized patients awaiting transplantation. Strict protocols requiring a negative prospective crossmatch before transplantation result in a decreased donor pool and a longer duration of support in sensitized LVAD recipients. Such patients are often denied an otherwise suitable donor because of a positive crossmatch. This policy can translate into a longer duration of mechanical support, with increased inherent morbidity such as stroke and infection.

John and colleagues from Columbia are to be commended for this significant contribution and their creative management of this difficult group of patients awaiting cardiac transplantation. Their large retrospective series of 520 adult cardiac allograft recipients included 105 patients who were supported with LVADs. Sixtyeight of the $105 \mathrm{LVAD}$ recipients, that is $65 \%$, acquired sensitization at the time of transplantation. Twenty-six sensitized LVAD recipients were treated with IVIg and cyclophosphamide before transplantation. The major findings of their study were as follows: (1) Sensitized LVAD recipients had an increased risk of acute rejection during the first year, and this was reduced by pretransplantation immunomodulation therapy. (2) There was no significant difference in posttransplantation survival or graft vasculopathy between LVAD and nonbridged recipients, regardless of the PRA level or the use of immunomodulation therapy. (3) Sensitized untreated LVAD recipients were less likely to receive transplants within 2 months than were nonsensitized LVAD recipients. This brings me to my first question. How much did your policy to perform a prospective crossmatch contribute to the prolonged waiting time of the sensitized untreated LVAD patients? Another way of asking is, would you consider intraoperative or perioperative plasmapheresis followed by IVIg to allow cardiac transplantation in sensitized patients without a prospective crossmatch?

Dr John. Actually, since the conclusion of the study we have performed cardiac transplantation in about 6 or 7 patients despite a positive crossmatch. All these patients had waited for prolonged periods because of repeated positive crossmatches, and their conditions were deteriorating while they were on the waiting list. As a result, we performed a retrospective crossmatch and went ahead with the transplant, treating the patients with plasmapheresis and, more importantly, perioperative IVIg with cyclophosphamide starting before transplantation. Six of these 7 patients survived, although 1 had repeated humoral rejections after transplantation, which we believe is important and is why we believe that doing prospective crossmatching is important.

Dr Razzouk. You report the highest incidence of allosensitization associated with LVAD support in the literature, 65\%. How often do you check the PRA, and have you noticed a decrease in the PRA with time? In other words, is this a transient sensitization?

Dr John. I think that several other groups have documented LVAD sensitization in the range of $40 \%$ to $60 \%$, and certainly we test PRA levels at monthly intervals in these patients. PRA levels are known to change with time. Thus it is our practice to check PRA levels at monthly intervals.

Dr Razzouk. My last question relates to the incidence of high-grade acute rejection among the sensitized patients during the first year after transplantation. Were those mostly humoral or cellular rejection episodes? And did the beneficial effect of IVIg and cyclophosphamide against rejection extend beyond the first 
year after transplantation? Should this group of sensitized patients receive more intense long-term immunosuppression and more rigorous surveillance after transplantation?

Dr John. The incidence of rejection refers to cellular rejection. The incidence of humoral rejection in this entire cohort of patients was remarkably low. Certainly, sensitized treated patients do receive more monitoring because of the implementation of the new protocol, close watch of their immunosuppression, and we believe that this contributes to the trend that we observed toward increased survival in the sensitized treated group of patients. Certainly the effect of IVIg and cyclophosphamide does not persist beyond the first year after transplantation, but I think that these patients go into the transplantation without these deleterious antibodies, and that gives them the maximum benefit.

\section{Online-www.aats.org}

Now you can get The Journal of Thoracic and Cardiovascular Surgery online. The Journal online brings you faster delivery time, easy searching of current and back issues, links to PubMed, AATS, WTSA, and other important sites, and more. Visit the Journal online today.

\section{Receive tables of contents by e-mail}

To receive the tables of contents by e-mail, sign up through our Web site at http://www.mosby.com/jtcvs

Choose E-mail Notification

Simply type your e-mail address in the box and click the Subscribe button.

Alternatively, you may send an e-mail message to majordomo@mosby.com.

Leave the subject line blank and type the following as the body of your message: subscribe jtcvs_toc

You will receive an e-mail to confirm that you have been added to the mailing

list.

Note that TOC e-mails will be sent out when a new issue is posted to the Web site. 